Pontifícia Universidade Católica $_{\text {mata }}$

DO RIO DE JANEIRO

Katja Linnemann

\title{
Angústia e objeto - elaborações a partir do caso de fobia Pequeno Hans
}

Dissertação apresentada como requisito parcial para obtenção do grau de Mestre em Psicologia Clínica ao Programa de Pós-Graduação em Psicologia Clínica do Departamento de Psicologia do Centro de Teologia e Ciências Humanas da PUC-Rio.

Profo. Marcus André Vieira

Orientador

Departamento de Psicologia - PUC-Rio 
Katja Linnemann

\section{Angústia e objeto - elaborações a partir do caso de fobia Pequeno Hans}

Dissertação apresentada como requisito parcial para obtenção do grau de Mestre em Psicologia Clínica ao Programa de Pós-Graduação em Psicologia Clínica do Departamento de Psicologia do Centro de Teologia e Ciências Humanas da PUC-Rio. Aprovada pela Comissão Examinadora abaixo assinada.

Profo. Marcus André Vieira

Orientador

Departamento de Psicologia - PUC-Rio

Prof ${ }^{\text {. Ana Maria Rudge }}$

Departamento de Psicologia - PUC-Rio

Prof'. Maria Silvia Garcia Fernández Hanna Escola Brasileira de Psicanálise - EBP

Prof. Paulo Fernando Carneiro de Andrade Coordenador Setorial de Pós-Graduação e Pesquisa do Centro de Teologia e Ciências Humanas - PUC-Rio

Rio de Janeiro, 17de fevereiro de 2006 
Todos os direitos reservados. É proibida a reprodução total ou parcial do trabalho sem autorização da universidade, da autora e do orientador.

Katja Linnemann

Graduou-se em Psicologia na PUC-Rio (Pontifícia Universidade Católica do Rio de Janeiro) em 1999. Especializou-se em Clínica Psicanalítica no IPUB/UFRJ (Instituto de Psiquiatria da Universidade Federal do Rio de Janeiro) em 2002.

Ficha Catalográfica

Linnemann, Katja

Angústia e objeto : elaborações a partir do caso de fobia Pequeno Hans / Katja Linnemann ; orientador: Marcus André Vieira. - Rio de Janeiro : PUC, Departamento de Psicologia, 2006.

100 f. ; $30 \mathrm{~cm}$

Dissertação (mestrado) - Pontifícia Universidade Católica do Rio de Janeiro, Departamento de Psicologia

Inclui referências bibliográficas.

1. Psicologia - Teses. 2. Angústia. 3. Fobia. 4. Objeto. 5. Estranho. I. Vieira, Marcus André. II. Pontifícia Universidade Católica do Rio de Janeiro. Departamento de Psicologia. III. Título.

CDD: 150 


\section{Agradecimentos}

À CAPES e à PUC-Rio, pelos auxílios concedidos, sem os quais este trabalho não poderia ter sido realizado.

Ao orientador Marcus André Vieira, pelas valiosas orientações, delimitações e sugestões. E principalmente por ter valorizado e sublinhado minhas construções.

A Marlene e Johannes Linnemann, que me transmitiram a importância da leitura, do estudo e da escrita.

A Sebastian Linnemann pelo carinho e pela ajuda na formatação.

A Raphael Milanez pelo amor, pela presença e pelo incentivo constante.

A Ana Lucia Lutterbach Holck, quem permite a tradução de minhas particularidades.

A Tatiane Grova pela cuidadosa revisão.

À querida equipe de pesquisa, pela rica troca ao longo destes anos: Tatiane Grova, Vânia Gomes, Teresa Pinheiro, Lourenço Astua, Rodrigo Lyra, Juliana Mercês, Carolina Martins, Laura Sarmento, Haendel Motta, Elisa Werlang, Clara Peed, Maria Novaes e Paula Mancini.

Às queridas amigas Vera Cristina e Issa Damous, com quem compartilhei tanto os momentos de angústia concernentes à escrita, quanto às conquistas neste processo.

Aos imprescindíveis amigos que acompanharam este percurso: Renata Perissé, Simone Delgado, Lorena Richter, Renata Del Caro, Uli, Daniela Pinto e Fernando Derenusson.

Às amigas e interlocutoras da psicanálise: Georgiana Gonçalves, Celina Guimarães, Cristina Frederico, Marícia Ciscato, Renata Martinez, Naiana Cordeiro.

À turma do ICP: Andréa Rolo, Beth Karam, Carlos Huszar e Fabrício Bueno.

Ao ICP e à EBP-Rio.

A Maria Silvia Hanna pela orientação do trabalho desenvolvido no ICP.

Aos professores de Pós-Graduação do Departamento da PUC-Rio.

Às secretárias do Departamento de Pós-Graduação em Psicologia Clínica da PUC-Rio. 


\section{Resumo}

Linnemann, Katja; Vieira, Marcus André (Orientador): Angústia e objetoelaborações a partir do caso de fobia Pequeno Hans. Rio de Janeiro, 2006, 100 p., Dissertação de Mestrado, Departamento de Psicologia, Pontifícia Universidade Católica do Rio de Janeiro.

De acordo com a teoria freudiana em sua abordagem por Lacan, os conceitos "angústia" e "objeto" são articulados sob dois aspectos na presente dissertação. Primeiro, a partir de um exame das considerações de Freud a respeito da fobia, que liga a angústia a um objeto na realidade. Com a formulação do "objeto $a$ " por Lacan, constata-se uma transformação do estatuto do objeto, uma vez que se trata de um objeto inconsistente. Exploramos, então, as possíveis relações entre a fobia do caso "Pequeno Hans" e tal objeto.

Palavras-chave: angústia, fobia, objeto, estranho. 


\section{Abstract}

Linnemann, Katja; Vieira, Marcus André (Advisor): Anguish and objectconsiderations based on the phobia case Little Hans. Rio de Janeiro, 2006, 100 p., Dissertation, Departamento de Psicologia, Pontifícia Universidade Católica do Rio de Janeiro.

According to Freud's theory and its interpretation by Lacan, the concepts "anguish" and "object" are articulated in two aspects in this dissertation. First, by examining Freud's considerations about phobia, that links anguish to an object in reality. With Lacan's formulation of "object $a$ ", we confirm a transformation of the statute of the object, as long as it treats of an inconsistent object. Then we explore the possible relations of phobia and the object in the case "Little Hans".

Key-words: anguish, phobia, object, strange 


\section{Sumário}

Introdução 9

$\begin{array}{ll}\text { Capítulo 1. Destinos do afeto } & 14\end{array}$

1. Considerações iniciais 14

2. As neuropsicoses de defesa 16

2.1 Histeria e neurose obsessiva 17

2.2 A fobia: uma defesa específica 18

2.3 O que escapa à defesa 20

3. Sintoma como formação de compromisso 21

4. O recalque 24

5. O sintoma fóbico 26

6. Reformulação da teoria da angústia 29

7. Do pai como perigo ao pai como função 30

8. Um novo estatuto para a angústia: a angústia vazia 31

Capítulo 2. Do pai presente ao pai como presença - Uma análise 35 da configuração subjetiva do Pequeno Hans

1. A potência opaca da mãe:uma relação de angústia 35

2. Da angústia ao medo e a saída pela fobia 40

3. O impasse edípico de Hans 42

4. A fobia: uma suplência à função paterna 44

5. Um objeto que porta a angústia 47

6. Circuitos 49

7. Duas manifestações do real $\quad 50$

Capítulo 3. Variações em torno da metáfora paterna 55

1. A metáfora paterna $\quad 55$

2. Catacrese $\quad 59$

3. A fobia e o mito como delimitação do real 63

Capítulo 4. Angústia e segredo 68

1. O pai impossível ou de um pai morto 68

1.1 A morte necessária de Don Juan $\quad 70$

2. Das Unheimliche e objeto a 72

2.1 Do corpo ortopédico ao corpo estranho 72 
2.2 O objeto como unheimlich: algo que não pertence à imagem 74

2.3 O estranho na literatura fantástica 76

2.4 "O Homem de Areia" 78

2.5 O olho e o objeto a $\quad 82$

3. Um lugar para o segredo 84

3.1 Segredo e unheimlich $\quad 84$

3.2 A mancha e o segredo 86

3.3 Que segredo para a fobia? 87

$\begin{array}{ll}\text { Conclusão } & 90\end{array}$

$\begin{array}{lr}\text { Referências bibliográficas } & 93\end{array}$

$\begin{array}{lr}\text { Anexo } 1 & 99\end{array}$

$\begin{array}{lr}\text { Anexo } 2 & 100\end{array}$ 